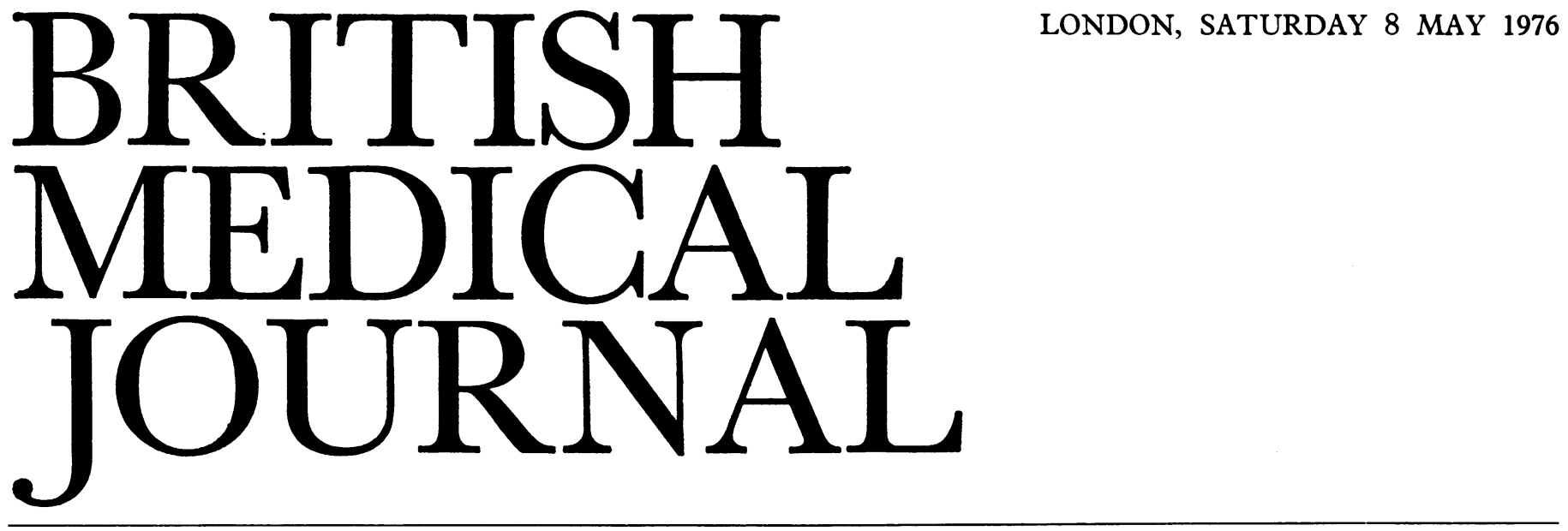

The introduction in 1967 of an offence based on a statutory blood alcohol concentration, associated with a screening breath test, led to a dramatic reduction in road accident mortality and morbidity. Over 1000 lives were saved in the first year after the Act $^{1}$ and an estimated total of 4000 in subsequent years. But the rate of casualty savings fell off progressively, and there are now bleak indications that the problem of drinking and driving is worse than ever. Before the Act about $25 \%$ of drivers killed in accidents were found to have had concentrations above the statutory $80 \mathrm{mg} 100 \mathrm{ml}$ limit. That proportion was reduced to $15 \%$ the year after the Act, but it had risen to $26 \%$ by 1971 and to $35 \%$ in 1974 . The age distribution is specially important. By $197140 \%$ of young drivers (in their 20 s) killed in accidents were found to have had alcohol concentrations above the statutory limit, and this had risen to $45 \%$ by 1974 .

What went wrong? From the start it had been clear that no adequate research had been done to identify and monitor which drivers drank and how much; that the screening procedures were defective; and that there was no provision to deal with high risk groups. The departmental committee set up under the chairmanship of $\mathrm{Mr} F$ Blennerinassett, $\mathrm{QC}$, to review the drinking-driving laws has now reported ${ }^{2}$ and has confirmed these inadequacies-but it has not explained why nothing was done about them. The answer lies in the rigid departmental attitude of successive Governments to road safety. The subject is never mentioned in the Department of Health's annual reports, though road accidents cause nearly half of all male deaths in the age group 15-24 and much permanent incapacity. The Department of the Environment takes an equally narrow attitude: it has not appointed a single medically qualified member to the committee which advises the Director of Road Research, whose resources should have been more widely deployed to deal with the problem of the drinking driver. On this basis it seems unlikely that those of the committee's recommendations which require liaison between the two departments will get very far: the "ad hoc" approach of road safety experts (recently summed up by a distinguished epidemiologist ${ }^{3}$ as "anything which sounds reasonable will be effective") may continue to hold sway.

The committee (see report of its proposals at $\mathrm{p} 1160$ ) has concentrated primarily on the agent-that is, alcohol. Consumption of alcohol has increased by $39 \%$ (even more among the young) between 1968 and 1974. Other alcohol-related offences and alcohol-related diseases have also increased rapidly. Drinking and driving should therefore be regarded as part of a wider problem of alcohol abuse. The concern expressed over proposals to alter licensing hours and to lower the age for drinking on licensed premises will affect yet another government department-the Home Office.

A second major factor has been defects in the screening procedure. The police have been fettered by unnecessarily complicated legal requirements attached to the breath testing procedure-described by the committee as an "artificial ritual"-and have been instructed not to concentrate their activities outside public houses, where drivers are most likely to be found above the legal limit. Furthermore, the legal loopholes in the Act have let many drivers avoid conviction. As Professor H L Ross, ${ }^{4}$ who has carried out the only comprehensive time-series analysis of casualty savings since the Act, has remarked: "The risk of apprehension for a drinking driver in Britain is realistically quite minute, and this fact is increasingly being learnt by the public, who are adjusting their behaviour in consequence." The committee's recommendation that the police should be given more discretion in taking screening tests is therefore welcome, as is its proposal that the new fuel cell devices should be evaluated with a view to replacing the relatively crude and inaccurate qualitative instruments in present use.

The committee has also proposed that the courts should accept evidence of the limit having been exceeded when it is provided by a quantitative breath test at the police station. The device used must measure concentrations reliably over a range including the critical points of $80 \mathrm{mg}$ and $200 \mathrm{mg} / 100 \mathrm{ml}$ (which is to be used to identify high-risk drivers) and must be capable of achieving accuracy within $\pm 10 \%$ at the $95 \%$ confidence level. Several instruments in use in other countries meet these requirements. An option to provide a confirmatory blood sample is proposed but is unlikely to be invoked by drivers, even in marginal cases, once it becomes generally known that breath methods usually underestimate blood alcohol concentrations. The procedure for cases in hospital would be simplified by abolishing the statutory screening test and by giving the police discretion to obtain samples of either breath or of blood. The option to provide a sample of urine would be abolished altogether. There can be no scientific objection to that. Nevertheless, it is recommended that urine samples be obtained where intoxication by drugs other than alcohol is suspected.

The committee goes on to recommend that "high risk offenders" should be identified in future by a special procedure. This group would include all drivers found to have had concentrations above $200 \mathrm{mg} / 100 \mathrm{ml}$. The proposal recognises the futility of automatically restoring a licence to an alcoholic after a year's disqualification, and the committee notes that one in 
ten convicted drivers repeat the offence within ten years-and an even larger proportion must have done so without being detected. The BMA recommended that a screening procedure for people at high risk should come into effect at $150 \mathrm{mg} / 100$ $\mathrm{ml}$, but the committee was influenced by "practical considerations": even at $200 \mathrm{mg} 100 \mathrm{ml}$ some 15000 drivers (including second offenders) would be included each year in the procedure, which requires drivers to provide evidence that they are no longer an undue risk before their licence is restored. Medical evidence will have an important part to play in this plan, so that it is unfortunate that so few doctors are available who are experienced in dealing with alcohol problems. It is as well to bear in mind that at $200 \mathrm{mg} 100 \mathrm{ml}$ we are talking about drivers who have taken 11-15 pints of ordinary beer or the equivalent in distilled spirits (11-15 "doubles") before driving. The committee's observation that this level "is hardly ever reached in normal social drinking" is therefore a gross understatement.

Of course, instruction in the safe use of the road system and the use of alcohol by young drivers should be regarded (as it is in other countries) as one of the most important functions of health education. The record of our road safety experts in this respect has been deplorable. The concentrated publicity campaign which accompanied the 1967 Act was never followed up, so that the very high risk group of young drivers (who represent the most serious problem today) have never been exposed to it and are mainly ignorant about the dangers of drinking and driving. Tragically, Graham Hill (a member of the committee) was killed in a plane accident before the report was published. We are told that he fully shared the committee's concern at the increasing toll of casualties caused by drinking and its desire to see urgent measures taken to reverse the trend. As a former world champion racing driver he would have done much to get the message across to the young.

This is a good report, and the committee's recommendations, which were unanimous and supported by the vast majority of those who submitted eviderice, could lead to a substantial reduction in mortality and morbidity. The report urges that the proposals be regarded as a package and not introduced piecemeal, so as to have the maximum impact. The main obstacle to this will be the vested interests of government departments. Perhaps we could learn a lesson from the French, who were so appalled by their road accident casualties that $M$ Girondeau, a young civil servant, was appointed to deal with the problem with direct responsibility to the Prime Minister overriding all government departments. The results were dramatic and have been lasting.

1 Road Safety Act 1967.

${ }^{2}$ Report of the Departmental Committee on Drinking and Driving (Mr F Blennerhassett, chairman). London, HMSO, 1976.

${ }^{3}$ Baker, S P, in Preventive Medicine and Public Health, 10th edn. New York, Appleton Century Crofts, 1973.

${ }^{4}$ Ross, H L, fournal of Legal Studies, 1973, $2,1$.

\section{Transposition of the great arteries}

In transposition of the great arteries the aorta arises from the right ventricle and the pulmonary artery from the left ventricle. This condition occurs once in approximately every 4500 live births $^{1}$; so that each year in Britain between 100 and 200 affected infants are born. In spite of its rarity it is the most common life-threatening cardiac disorder encountered in the first month of life. Without treatment half the infants with transposition die in the first month, and less than $10 \%$ will survive to the age of 1 year. ${ }^{12}$

The basic problem in transposition is that the pulmonary and systemic circulations are separate and life is maintained only by communications which allow mixing of blood from the two circuits. The usual approach to treatment has been to perform a palliative operation to improve this mixing by creating an atrial septal defect. This was originally performed surgically, ${ }^{3}$ but more recently a balloon catheter has been used to enlarge the foramen ovale. ${ }^{4}$ The operation is done as soon as the diagnosis is established-in fact with the balloon technique it is generally performed at the diagnostic cardiac catheterisation. With balloon septostomy $70 \%$ of patients will survive the first year of life, but in most centres corrective surgery is performed electively between 6 months and 1 year of age. Up to the present the Mustard operation ${ }^{5}$ has been the corrective operation of choice in most patients. The interatrial septum is refashioned so that systemic venous blood is directed to the lungs via the left ventricle and pulmonary artery and the oxygenated pulmonary venous blood is directed to the body via the right ventricle and aorta. This operation can be performed with a low mortality, ${ }^{6}$ and in the intermediate term the majority of children lead full normal lives. Since, however, the basic anatomical lesion is not dealt with, the Mustard operation is not corrective in the strict sense of the word. Complications such as tricuspid incompetence have been encountered in a minority of patients and raise doubts about the ability of the right ventricle to serve as the systemic arterial ventricle for a normal life span.

Surgeons have therefore recently re-explored the direct approach to the correction of transposition by transferring the aorta to the left ventricle and the pulmonary artery to the right ventricle. Operations of this type were attempted without success $^{7-9}$ in the 1950 s and 1960 s. These early failures were in part due to deficiencies in cardiopulmonary bypass techniques and inadequate postoperative care, but with the general development of infant cardiac surgery these inadequacies have been overcome. One major problem remained unsolved: the technical difficulty of transferring the coronary arteries with the aorta. The two articles in this issue at pages 1109 and 1112 show that this technical difficulty has now been overcome.

This evidence that an arterial relocation operation can be successful raises the question of the place of such operations in the treatment of transposition. Relocation has limitations: such operations can be performed only in patients whose left ventricle sustains pressures similar to those encountered in the systemic arterial system but who have not developed severe pulmonary vascular disease.

Soon after birth regression of the fetal pulmonary vasculature leads to a fall in pulmonary vascular resistance, and unless a large ventricular septal defect or persistent ductus arteriosus is present, or there is pulmonary stenosis, in cases of transposition this change will result in a fall in left ventricular pressure and a diminution in left ventricular mass. ${ }^{1011}$ After the first week or two of life, therefore, half the infants with transposition will have left ventricles incapable of sustaining systemic arterial pressures. In such cases relocation operations would have to be performed in the early neonatal period. Even when the technical problems of arterial relocation in very young infants have been overcome, however, a substantial number of patients will not be referred to specialised centres until after their left ventricular mass has declined. These two reports of arterial relocation operations herald a new era in the 